\title{
Research Incentive Mechanism of Knowledge Staff Based on the Psychological Contract
}

\author{
Han Xinliang \\ Department of electronic commerce, \\ Sichuan vocational college of science and technology, \\ Chengdu 610031, China \\ e-mail: 1466155063@qq.com
}

\begin{abstract}
With the development of knowledge economy in our country, bearing the knowledge, skills, knowledge, information, technology, knowledge workers as the producers, become the main creative power of the enterprise value. In the modern management, the knowledge staff has become the strategic resource of enterprise competitive advantage. Therefore, how to effectively motivate knowledge workers, give full play to the initiative and enthusiasm of their work, make its maximum creativity, enhance the enterprise the competitive power is an important proposition in the 21st century, the new economy. An incentive of knowledge workers in addition to the economic contract, more important is to establish a kind of psychological contract between organization and employee. This article from the theory of psychological contract, under the guidance of equity theory, incentive theory, etc, it is concluded that the knowledge employees' psychological contract; At the same time, the knowledge employees' psychological contract is divided into transactional psychological contract and relational psychological contract and development-oriented psychological contract three dimensions; Finally, from the perspective of the above three dimensions, respectively, and the corresponding incentive mechanism is put forward.
\end{abstract}

Keywords-psychological contract; The enterprise management; Human resource management;The knowledge staff; Incentive mechanism

\section{INTRODUCTION}

Knowledge is the basic economic resources of the society. It is no longer capital, natural resources or labor, it is now and in the future is knowledge. Enterprises have the knowledge staff, is more likely to get a steady stream of competitiveness. It is a kind of inevitable phenomenon that interdependence and restricts mutually between knowledge workers and organizations, this relationship is constrained to the game between the employees and the organization. Both sides want to maximize their own interests. In order to guarantee the harmonious development of the relationship, need to have a intermediates to restriction on both sides, make both sides can maintain a relatively stable state, with respect to the manner of action each other mutual trust, which requires the organization and employees to create a positive balance between the psychological contract.

Although psychological contract is to understand the framework of employment relationship is the most important, but with the change of environment and the uncertainty of

Sponsor: The natural science foundation of Science and Technology Agency of Sichuan province, (2014FZ0112). enhancement, employees often feel organization failed to fulfill its responsibility. So when organizations failed to fulfill the responsibility, psychological contract violation or may make employees leave. [1]More and more workers, especially the young employees, advocating the brief and temporary employment relationship. [2] These in the final analysis is the organization of knowledge staff incentive effect. Management psychology research shows that: in the condition of not fully motivate employees, play the ability of less than $30 \%$ of their own capabilities, and in the condition of fully the right incentives, the ability to play can reach more than $80 \%$.[3-5]

This article from the perspective of psychological contract choice, based on psychological contract analysis tools to study the enterprise knowledge staff incentive mechanism problem" by studying the knowledge employees' psychological contract content, can help enterprises to understand knowledge staff psychological demand characteristics, as well as the organization what effective management behavior should be taken to improve the psychological contract between the employee with knowledge, to develop and implement effective incentive strategy accordingly.

\section{THE CONNOTATION OF PSYCHOLOGICAL CONTRACT AND KNOWLEDGE WORKERS}

\section{A. The Concept and Characteristics of Psychological Contract}

Psychological contract is the organization and employees in the employment relationship, the two sides agreed upon in advance, but there is no performance of various expectations. Before the enterprises and individuals out there is a no show, implicit agreement, both sides hope that through efforts to the other party, what should be, this is the "psychological contract". Psychological contract is defined as "any organization, each member with the organization's between managers and others, always have a written expectations at work "unconscious". the psychological contract is divided into two parties, individuals and organizations, and that psychological contract exist within the organization and staff, is both sides think the other party should provide a variety of responsibility of a sensory understanding, the sensory awareness or hidden in various expectations, or from the perception of behavior. 
In this paper, the psychological contract is defined as: the expectations of both organizations and individuals to each other and responsibility of a kind of subjective psychological agreement, key components of contract is implied in the both sides informal mutual responsibility and expectations. Psychological contract is different from the economic contract, has the following features:

Psychological contract is an incomplete contract form. Employees are bounded rationality, at the same time, the internal and external environment and has the complexity and uncertainty, so the information obtained by the two parties are incomplete and asymmetric back, thus, individual through to encode information gained by the expectations and responsibilities of each other's understanding is incomplete.

The psychological contract of subjectivity. Because of the psychological contract is more emphasis on both sides of the psychological expectations, one party want to another party, namely obtained from the other party, this evaluation of pay and income is related to perception, owing to the different individual needs, thus with the composition of subjective judgment.

The dynamic psychological contract. Formal economic contract in general are more stable, but the psychological contract is relatively in a state of changing, any organization adjustment, will affect their identification of the psychological contract.

The core content of psychological contract is the mutual exchange relationship between responsibility and expectations, of course, this kind of exchange content is not limited to the exchange of material, also includes feeling, the achievement of psychological and exchange, the exchange on the basis of the principles of fairness. Only through mutual exchanges and communication between the two sides, reach a consensus on the development of organizations and individuals, to give play to the role of psychological contract incentive, meet the needs of both sides.

\section{B. The Concept of Knowledge Workers and Characteristics}

Peter drucker, is the first to put forward the concept of knowledge workers, he thinks that knowledge workers are those who master and use symbols and concepts, the use of knowledge or information work. And points out that one party and knowledge workers can make full use of modern scientific and technological knowledge to improve work efficiency, the other party and knowledge workers themselves and have strong learning and innovation knowledge

The ability of fiat. This study thinks that knowledge staff refers to the organization, which is based on knowledge, through mental work, contributing to an innovative organization, currency capital rapid appreciation, to create a continuous competitive advantage for organization. Distinguish in specific industry, senior management personnel of enterprises, scientific research personnel, senior sales personnel and some technical research and development Member. Knowledge workers compared with the general staff, however, has its own characteristics.
Knowledge workers engaged in is not simple and repetitive work, but in a volatile and not entirely sure system, give full play to the personal qualifications and inspiration to all kinds of possible situation, promote the technology progress, and constantly to update products and services.

\section{Psychological ANAlysis of THE KNOWLEDGE EMPLOYEES' PSYCHOLOGICAL CONTRACT}

\section{A. The Knowledge Employees' Psychological Contract Dimension}

Psychological contract can be defined as: in group a employee relations, knowledge workers by commitment to the organization policy, culture, and the understanding of the parties, such as the feel of their respective obligations and responsibilities. The knowledge employees' psychological contract is the responsibility of the books and organize a staff exchange, reflect the knowledge staff and organizational fit.

The role of the knowledge staff to promote organizational development, enterprises must proceed from the characteristics of knowledge workers, through the study of the psychological contract of knowledge staff analysis, studies the knowledge employees' psychological contract dimensions, and on this basis, summed up the characteristics of psychological contract, according to its particularity, set up a corresponding incentive mechanism.

About the psychological contract structure of knowledge workers, the structure of the scholars have a three-dimensional structure, the structure of the $2 \mathrm{~d}, 3 \mathrm{~d}$ structure and multidimensional structure. Research shows that, in the psychological contract of the two dimensional celebrates the department structure composition and trading into strength also includes team members on the basis of dimensions, which is a good interpersonal relationship between the organization and its members and employees work environment. Team members dimension reflects the employee's pay more and more attention to the personal growth trends in the organization. At present domestic scholars on the study of the structure of psychological contract conclusion is not consistent, but identity is more three-dimensional structure, namely transaction dimension and relation dimension and development dimension. Therefore, this article divide the psychological contract of knowledge workers as the three dimensions.

Transaction dimension is mainly refers to the organization to provide staff economic and material benefit, these interests is concrete, mainly including salary, good working conditions, etc. Relationship dimension is mainly refers to the organization to provide staff exchanges and cooperation and mutual contact of the platform, organization members can feel the feelings of concern, enhance the sense of belonging; Development dimension mainly refers to the organization from the perspective of employee career development for staff to provide a series of contribute to the career development services, these services a wide range, long duration and main job enrichment, such as career development opportunities. 


\section{B. The Knowledge Employees' Psychological Contract}

To master the knowledge employees' psychological contract characteristics is the precondition of management and effective incentive. Knowledge employees' psychological contract is different from the ordinary employee, has its inherent characteristics:

First, the knowledge workers have higher fairness perception of transactional psychological contract is more sensitive to their perception of fairness, pay more attention to the fair treatment of the organization, looking forward to an organization to pay more attention to fair process.

Second, the knowledge staff especially attaches great importance to the relational psychological contract and development-oriented psychological contract. Knowledge workers have its own high quality determines their pay more attention to a high level of demand, only meet the needs of the high level to make myself to get the greatest satisfaction, so as to maximally mobilize their enthusiasm.

\section{UNDER DIFFERENT PSYCHOLOGICAL CONTRACT DIMENSION OF KNOWLEDGE STAFF INCENTIVE MECHANISM}

\section{A. Incentive Mechanism Based on Transactional Psychological Contract Dimension}

In the knowledge employees' psychological contract management, to solve the key question is how to make the knowledge staff is an objective for organizations to perform the contract, a positive evaluation, and make positive response on the attitude and behavior, which is fit with the goals of incentive method to knowledge employee. Visible, psychological contract

About management and the knowledge staff motivation is highly consistent, complementary to each other. So in order to achieve, everyone has something to do, someone to do everything", play the ability of employees as far as possible, requirements on the basis of above study, according to the characteristics of the knowledge employees' psychological contract, from the perspective of their $3 \mathrm{~d}$ psychological contract, building the appropriate incentive mechanism.

Fairness is the basis of the performance appraisal system Settings, is the basic principle of incentive process. Employees in the organization will always be their own input/output or input/output of the others of his past input/output compared to measure back. On the need for a fair degree of knowledge workers more strongly than general staff, hope you can have a price in the organization value, to that end, organizations can set fair quantitative evaluation system for knowledge workers, quantitative assessment is the basic steps:

For knowledge workers, pay has become a kind of highlevel achievement desire on demand. Incentive compensation can more meet the needs of knowledge workers, makes the compensation can be an effective factors of the incentives. But this needs based on a variety of elements, with a compensation formula can be expressed as:

$\mathrm{MP}+\mathrm{BP}+\mathrm{CP}+\mathrm{FS}+\mathrm{SW}$
Based on the holder's basic salary. Is no longer according to the work to determine the compensation, but learning, ability, skills, etc according to the incumbent party and to determine the pay difference, it is based on the incumbent skill, the ability to improve, with the adjustment of the jobs and job responsibility into rich means, the final is on the basis of job analysis and responsibility, to determine the degree of job enrichment and expansion of the knowledge-type employees.

Competitive compensation. Knowledge workers will be the same position with other industry enterprises pay levels are compared, in order to measure their pay level is high or low, whether or not they treated group is better. Therefore, enterprises need to know in carrying out pay market research and enterprise oneself circumstance, on the basis of provide employees with competitive salary, at the same industry which is needed to set pay appropriate compensation levels higher than market, namely the organization adopted a policy of compensation leader\} 0] now figure township. Organization in determining the wage level, of course, at the same time, should pay attention to the enterprise total amount and the balance between the ability to pay, to establish satisfy the need of market competition and is beneficial to the organization for the long-term development of above market pay levels of compensation.

Flexible bonus system. The form of a bonus can vary, according to the law of diminishing marginal utility, long-term pure money temptation to the knowledge staff's appeal is more and more weak, the effect of incentives also drops, enterprises should fully tap recessive capital, knowledge staff is the reward for them could decrease the cash rewards, and more using ESO P two-string fiddle workers holding meter Bob to be in the form of incentive.

The elastic welfare style welfare system. Knowledge staff values orientation of pluralism and diversity decided the welfare of fixed plan doesn't meet their needs, therefore, to provide them with elastic welfare policy - buffet style welfare system. This kind of elastic welfare plan of the biggest advantage is its flexibility to meet different employees need to motivate knowledge workers of each party and effect.

Salary incentive has an important role in knowledge employees psychology is not only the material, more represents the identity, status, personal value, and its performance in the company and personal development prospects. From the perspective of psychological contract, these psychological satisfaction from the ego needs, desire to be respected, the organization's support and recognition, and personal career development, inspire the ultimate effect of that knowledge workers is considered organization respect and implements its commitment to the psychological contract content, thereby significantly reducing the occurrence of the phenomenon of violation of psychological contract.

\section{B. The Incentive Mechanism Based on Relational Psychological Contract Dimension}

When employees perceive higher perceived organizational support, easy to cause psychological contract violation. Even without effective responsibility, employees will benefit attribution and explain\} 1) of the organization. So the 
knowledge staff is eager to get the organization's approval, hope to establish a good relationship with the organization, made itself development together with the organization. However, Knowledge workers with the enterprise the establishment of this relationship and maintain the need to build a set of incentive mechanism from inside to outside a mouth.

The generation of psychological contract should be based on the enterprise culture, the establishment of the enterprise culture also depends on the psychological contract of employees in enterprises, especially for the enterprise knowledge staff. A good enterprise culture can improve staff work enthusiasm and motivation, inspire an enterprise and the staff to perform the contract. Enterprises should create a people-oriented corporate culture atmosphere to support the psychological contract

Around the building. Good enterprise culture can make all the staff of the psychological contract towards a unified direction. Enterprises should make full play of the all employees' ability, do people do all it can, do all in its use. To create corporate culture more conducive to the development of psychological contract to improve employee satisfaction.

MIT professor Peter Senge C009) in the study think that the learning organization is an organization like this: in the organization, members can break my ability limit, creation and its own satisfactory results, and achieve common wishes. He believes that the learning organization goal is to improve the ability of learning, speed, etc., through the establishment of vision and be able to

Finding and improvement of the organization's thinking mode and thus change the behavior of the members. Senge also puts forward the practice of "five" model of establishing the learning organization: self transcendence, improving mental models, building Shared vision, group learning and systems thinking. This model is able to motivate employees to all organizational activities process, function and interaction in the environment

Thinking, break the conventional ways of thinking, through mutual honest attitude and communication way to come up with an idea for a group approval together, and is willing to pay the effort $\mathrm{oz}<\}$.The establishment of a learning organization is between members of the organization to build a platform of study and improve together, through the joint efforts of all employee, makes the organization's goals and personal goals are achieved.

Rosenthal effect on incentive revelation: everyone wants to get recognition and praise, with actions, emotions give positive evaluation information can make knowledge workers feel from the organization's concern, so can make the employees to become more aggressive, to achieve greater progress. Therefore, the organization shall timely for knowledge-based employees to give praise, for their

Points, multi-purpose use less criticism, praise to their expectations, they suggest that organization can make their physical and mental are great satisfaction, meet their sense of achievement, make its creative naturally, so as to make the organization's goals.
Knowledge staff stressed self management, autonomy have higher requirements for its own work, especially in a business method, the workplace, working hours and, because, to make knowledge workers in working content and working environment and have certain right to speak, in its organization, to the extent permitted to self control and self learning and self management, so as to play its innovation ability.

\section{The Incentive Mechanism Based on Developmental Psychological Contract Dimension}

Different from traditional material incentive, incentive method to knowledge talent for knowledge workers, the work itself a sense of accomplishment and self growth can arouse their working enthusiasm, more achievements in the organization can let them get more motivation and satisfaction. And enterprises should attach importance to the training of the knowledge-type employees, to ensure that the organization have timely information and advanced technology, make its ranks at the forefront of the industry, and promote the overall growth of industry fza7.Organization, therefore, at the same time of development, both must implement positive training for employees, and carries on the career planning and management.

\section{1) Training and development}

The power of the development of employee training is to help employees to grow. With the economic globalization, virtual organization structure, organization structure, flattening organization change, such as making concluded relationship between enterprises and employees to work from the traditional through hard work in return for the payment way of psychological contract are gradually on the basis of training the core way of psychological contract. Thus, strengthen the training of the knowledge staff knowledge and skills, is to establish the key to winning the psychological contract of employees and enterprises.

\section{2) The career planning and management}

The development-oriented psychological contract emphasizes the knowledge-type employees, and thus is more concerned with their own career planning. Enterprise to career planning and management of knowledge workers, to help them better development in the direction of the organization's goals, arouse their working enthusiasm and initiative, in the realization of organizational goals at the same time, also can satisfy the knowledge staff a sense of achievement and satisfaction. Therefore, in this sense, the enterprise through the knowledge staff's career planning and management, can meet the needs of the individual knowledge workers, also can meet the needs of the organization goal and its development, combine the good, can achieve the purpose of the enterprise value and individual value win-win.

In organization, knowledge workers because of the different knowledge structure, ability structure, its demand is diverse, and the expectations of organization is the different, this determines the personalized incentive way above fz57 incentive mechanism should be taken from the $3 \mathrm{~d}$ in the research of the perspective of psychological contract, in the process of implementation of incentive, the first fully 
communication with knowledge staff, realizes the information sharing and smooth communication channel and the demands for the interests of employees to set up proper expression platform. From them to know that the real demand to determine the weight of all kinds of psychological contract in the knowledge staff; Then according to the weight of different psychological contract dimension of the knowledge-type employees, the implementation of incentive, at the same time, meet the demand of knowledge workers and give them guidance, making it develop towards organizational objectives, so as to make the employee goals and organizational goal to double.

\section{CONCLUSION}

Current research on the knowledge employees' psychological contract is an important part of the new subject, this article, based on the perspective of psychological contract, from the connotation and the characteristics of the knowledge workers, the psychological contract has carried on the detailed argumentation of the knowledge-type employees, and explores the connotation and characteristics of incentive method to knowledge employee, and combining with incentives based on the knowledge employees' psychological contract dimension.

In today's knowledge, the information era, and decisive factors of the core competitiveness of enterprises to obtain and maintain will increasingly depend on the knowledge staff's creativity. As far as possible and reduce the loss of talents and motivate knowledge workers, prompting them to have the knowledge, skills and creativity really into enterprise core competitiveness is human resources management in a very important subject. Managers should fully understand the psychological contract of knowledge workers and organization of the special relationship, and combined with economic contract, design the appropriate incentives, so as to achieve the best effect of incentive method to knowledge employee., in short, any incentives must be from the knowledge staff's own characteristics, study the demand, grasp the psychological characteristics, elaborate design organizational environment conducive to the development of knowledge workers, establish an effective incentive mechanism and behavior, can really meet the requirements of the interior and the exterior of employees, fully arouse the enthusiasm and creativity of knowledge workers, work play its unlimited potential, making it fully integrated into the enterprise culture, with the development of enterprises grow together, to interests of employees and enterprises in the true sense of "win-win".

Author introduction: Han Xinliang, male, was born in 1966, Ph.D, professor. Main research direction for the human resource management, intelligent optimization control algorithm. He has published over 20 papers. He has one provincial scientific research projects.

\section{REFERENCES}

[1] De Vos,A. \& Buyens,D. Managing the Psychological Contract of Graduate Recruits:A Challenge for Human ResourceManagement [J].Vlerick Leuven Gent Management School,2001.

[2] Zhang bin. Psychological contract theory and the knowled gestaff management [J].Shandong Social Science,2006(11):145-146.

[3] Tekleab A G,Takeuchi R,Taylor M S. Extending the Chain of Relationship samong Organizational,Justice,Social Exchange and Employee Reactions:The Role of Contract Violations[J].Academy of Management Journal,2005(48):146-157.

[4] Morrison EW,Robinson S L. When Employees Feel Betrayed:A Model of How Psychological Contract Violation Devel-ops [J].Academy of Management Review,1997(22):226-256.

[5] Guest D E. Is the psychological contract worth taking seriously [J].Journal of Organizational Behavior,1998(19):649-664. 